\section{Role of Growth Regulators in In Vitro Rhizome Growth of Potato}

\author{
B.Z. Escalante ${ }^{1}$ \\ Tissue Culture Laboratory, National University of Cajamarca, Cajamarca, \\ Peru
}

\author{
Alan R. Langille ${ }^{2}$ \\ Department of Applied Ecology and Environmental Sciences, University of \\ Maine, Orono, ME 04469
}

Additional index words. gibberellic acid, indoleacetic acid, tissue culture, tuber ontogeny, Solanum tuberosum

\begin{abstract}
Disinfested, etiolated medial segments of potato (Solanum tuberosum L.) sprouts cv. Katahdin with two axillary buds were placed on Murashige and Skoog (MS) medium in clear plastic culture boxes. Basal ends of explants were inserted into MS medium containing BA at 2 mg.liter ${ }^{-1}$. Nine treatments, composed of factorial combinations of $\mathbf{G A}_{3}$ at $0,0.2$, and 2 mg.liter $^{-1}$ and IAA at $0,0.3$, and $3 \mathrm{mg}$.liter ${ }^{-1}$, were imposed. These were applied via small agar cylinders placed on the apical cut surface of each segment. Regardless of the presence of cytokinin and auxin, no rhizomes developed after 3 weeks in culture without a supply of $\mathbf{G A}_{3}$. Number and length of primary and secondary rhizomes increased with an increase in $\mathbf{G A}_{3}$ concentration in the agar cylinder from 0 to 2 mg.liter $^{-1}$. Rhizome initiation and development appear to be controlled by coordinated participation of endogenous plant hormones during the early events leading to tuber development. Chemical names used: 2,4a,7-trihydroxy-1-methyl-8-methylenegibb-3-ene-1,10-carboxylic acid 1->4 lactone $\left(\mathrm{GA}_{3}\right)$; indole-3-acetic acid (IAA); $N$-(phenylmethyl)-1H-purin-6amine (BA).
\end{abstract}

The definitive factors controlling tuber formation in the potato plant have eluded scientists for more than a century. Formation of the potato tuber involves two distinct yet closely related processes: development of the rhizome and tuberization of its subapical region (Booth, 1963). Since rhizome development is a prerequisite to normal tuber formation, it is important to ascertain the factors involved in rhizome ontogeny from an axillary bud.

Rhizomes are diageotropic shoots with elongated internodes that may form at any lateral bud (Booth, 1963; Kumar and Wareing, 1972), usually at the most basal nodes of the sprout and developing in acropetal succession (Booth, 1963; Plaisted, 1957).

Booth (1963) observed that adventitious root development always preceded rhizome emergence at basal nodes. When a combination of IAA/gibberellic acid (GA) in lanolin paste was applied to the cut surface of a decapitated shoot of Solanum andigena Hawkes,

Received for publication 3 Apr. 1995. Accepted for publication 6 July 1995. Maine Agricultural and Forest Experiment Station Publication no. 1939. B.Z.E. is grateful to the Latin American Scholarship Program of American Universities (LASPAU) for providing support during graduate studies at the Univ. of Maine. The research was supported by funds provided to the Maine Agricultural and Forest Experiment Station under provisions of the Hatch Act. The cost of publishing this paper was defrayed in part by the payment of page charges. Under postal regulations, this paper therefore must be hereby marked advertisement solely to indicate this fact. ${ }^{1}$ Assistant Professor and former Graduate Assistant. ${ }^{2}$ Professor; to whom reprint requests should addressed. the bud at the uppermost node developed as a diageotropic rhizome. Rhizome development also was stimulated by introducing $10 \mu \mathrm{g} \mathrm{GA}$ in EtOH through a capillary tube at the base of an intact dark-grown tuber sprout. Other researchers (Kumar and Wareing, 1972; Wooley and Wareing, 1972a, 1972b, 1972c) treated decapitated shoots and shoot cuttings with hormone combinations to study rhizome development at aerial buds. They concluded that for lateral buds not subject to apical dominance, a low ratio of cytokinin : gibberellin favors rhizome development, while the reverse favors production of leafy shoots. Kumar and Wareing (1972) advanced a theory that attempted to explain potato rhizome growth as it relates to plant hormones and proximity to their individual sites of synthesis.

If GA plays a role in rhizome initiation and growth, one would expect its relative levels to be elevated under environmental conditions under which rhizome growth is greatest. Chapman (1958) observed that rhizomes were more plentiful and longer when potato plants were grown under long days, and Okazawa (1960) found that gibberellin levels were highest in potato plants grown under long days. According to Forsline and Langille (1976), bud elongation was significantly more prevalent in cultured nodal stem segments taken from noninduced than from induced 'Katahdin' potato plants. Buds on apical stem segments elongated to form rhizomes more frequently than did buds on segments taken from the basal stem position. Since gibberellins are known to be synthesized in apical buds (Jones and Phillips, 1966) and to a greater extent under noninducing conditions, GAs might be expected to play an important role in controlling rhizome elongation.

The following study was initiated to assess the applicability of the Kumar and Wareing theory when attempting to simulate hormone production sites in vitro.

\section{Materials and Methods}

Plantmaterial. Etiolated 'Katahdin' sprouts were obtained by planting whole tubers in flats filled with moist perlite and incubating at $28 \mathrm{C}$, as described by Forsline and Langille (1976). When sprouts were $\approx 25 \mathrm{~cm}$ long, a medial 5$\mathrm{cm}$ portion containing two axillary buds was excised from each sprout. Sprout segments were surface-sterilized using a Clorox, ethanol, sterile water sequence, as described by Forsline and Langille (1976).

In vitro culture. Disinfested sprout segments were trimmed to $4 \mathrm{~cm}$ in a sterile transfer hood. Their basal ends were inserted $\approx 1 \mathrm{~cm}$ into growth medium in clear plastic culture boxes (GA7; Magenta, Chicago), with one segment per box. Media used were of two types: 1) growth medium, $50 \mathrm{ml}$ in each culture box; and 2) apical cylinder medium, 9$\mathrm{mm}$ diameter $\times 10$-mm agar disks containing the exogenous hormones. In both cases, media consisted of Murashige and Skoog (1962) salts (MS) supplemented with $2 \%$ sucrose, plus (mg.liter ${ }^{-1}$ ) 100 inositol, 5 thiamine- $\mathrm{HCl}$, and $2 \mathrm{Ca}$-pantothenate. The growth medium contained BA at $2 \mathrm{mg} \cdot$ liter $^{-1}$, since preliminary studies had shown that BA was required for rhizome initiation (unpublished results). Apical cylinder medium had the same composition as the growth medium, except that it contained IAA and $\mathrm{GA}_{3}$, but lacked BA. Treatment hormones were represented by IAA at 0 , 0.2 , or $2.0 \mathrm{mg} \cdot \mathrm{liter}^{-1}$ and $\mathrm{GA}_{3}$ at $0,0.3$, or 3.0 mg.liter ${ }^{-1}$, which were applied in a factorial combination. In all cases, filter-sterilized hormones were added to the appropriate medium after it had cooled to 50 to $60 \mathrm{C}$. Media were adjusted to $\mathrm{pH} 5.6$ and solidified with $0.8 \%$ Difco agar (Difco, Detroit). Following insertion of the basal end of the sprout segments into the growth medium, the hormone-enriched cylinders were placed on their apical cut surface (Fig. 1). Each treatment was replicated nine times, including the control, and the experiment was conducted twice.

Culture boxes containing the treated segments were placed in a darkened incubator adjusted to 24C. Cultures were examined weekly for contamination and evaluated for rhizome development after the third week. At that time, explants were removed from the culture box and the number and length of primary and secondary rhizomes produced per axillary bud were recorded. Rhizomes from each explant were excised and their fresh weight determined. Since treatments containing no $\mathrm{GA}_{3}$ resulted in no measurable response, these were not considered in the statistical analysis. The remaining data set was not normally distributed; thus, it was ranked and analyzed as a completely randomized design. Original data were used to present results corresponding to each response variable. 


\section{Results}

IAA concentration had no significant effect on initiation and development of primary rhizomes. Since the IAA $\times \mathrm{GA}_{3}$ interaction also was nonsignificant $(P \leq 0.05)$, only the significant $\mathrm{GA}_{3}$ main effects on primary rhizome number will be considered. Rhizomes were not formed in the absence of $\mathrm{GA}_{3}$, but addition of $\mathrm{GA}_{3}$ to the medium resulted in rhizomes that increased in number and length with increasing $\mathrm{GA}_{3}$ concentration (Table 1). Use of 2 mg.liter ${ }^{-1}$ was associated with significantly more and longer rhizomes than 0.2 $\mathrm{mg} \cdot \mathrm{liter}^{-1}$. For example, primary rhizomes from the $2-\mathrm{mg} \mathrm{GA}_{3} /$ liter treatment were $62 \%$ longer than those from the $0.2-\mathrm{mg} \mathrm{GA}_{3} /$ liter treatment.

Neither IAA concentration nor the combined effect of IAA $\times \mathrm{GA}_{3}$ had any significant effect on number and length of secondary rhizomes. Increased $\mathrm{GA}_{3}$ concentration, however, was associated with significant increases in number and length of secondary rhizomes (Table 1). As for primary rhizomes, more and longer secondary rhizomes were associated with the highest $\mathrm{GA}_{3}$ concentration when incorporated into the agar cylinder. Secondary rhizomes were $37 \%$ longer with $\mathrm{GA}_{3}$ at 2 mg.liter ${ }^{-1}$ when compared with $\mathrm{GA}_{3}$ at 0.2 mg.liter ${ }^{-1}$.

The stimulatory effect noted for the higher $\mathrm{GA}_{3}$ concentration also was expressed in the total fresh weight of rhizomes (Table 1). $\mathrm{GA}_{3}$ at $2 \mathrm{mg}^{-1 i t e r^{-1}}$ was associated with a $20 \%$ increase in total rhizome weight relative to 0.2 mg.liter ${ }^{-1}$.

\section{Discussion}

Kumar and Wareing (1972) proposed the following scheme for potato rhizome development: the apical bud supplies sufficient auxin to suppress axillary buds above the soil surface, yet permits more distant, below-ground buds to be released. The gibberellins produced by immature leaves in the terminal bud then stimulate elongation of the released bud, resulting in a rhizome. They initially proposed that cytokinins produced by adjacent roots would convert the developing rhizome to a leafy shoot. However, they concluded that rhizomes develop in the below-ground region where roots are located because the cytokinins produced by the roots are directed upward toward the intact apical bud.

Although, the effects of IAA concentration were nonsignificant, IAA had been included to simulate apical dominance, a presumed prerequisite to rhizome development (Booth, 1963). We also included BA in the growth medium at a concentration determined from our preliminary experiments to stimulate bud growth. This level was insufficient to produce the upright, leafy shoots observed at higher cytokinin concentrations (Kumar and Wareing, 1972). Our observation that $\mathrm{GA}_{3}$ concentration was the important factor controlling rhizome initiation and growth is consistent with those of Kumar and Wareing (1972).

HortScience, Vol. 30(6), OCtober 1995

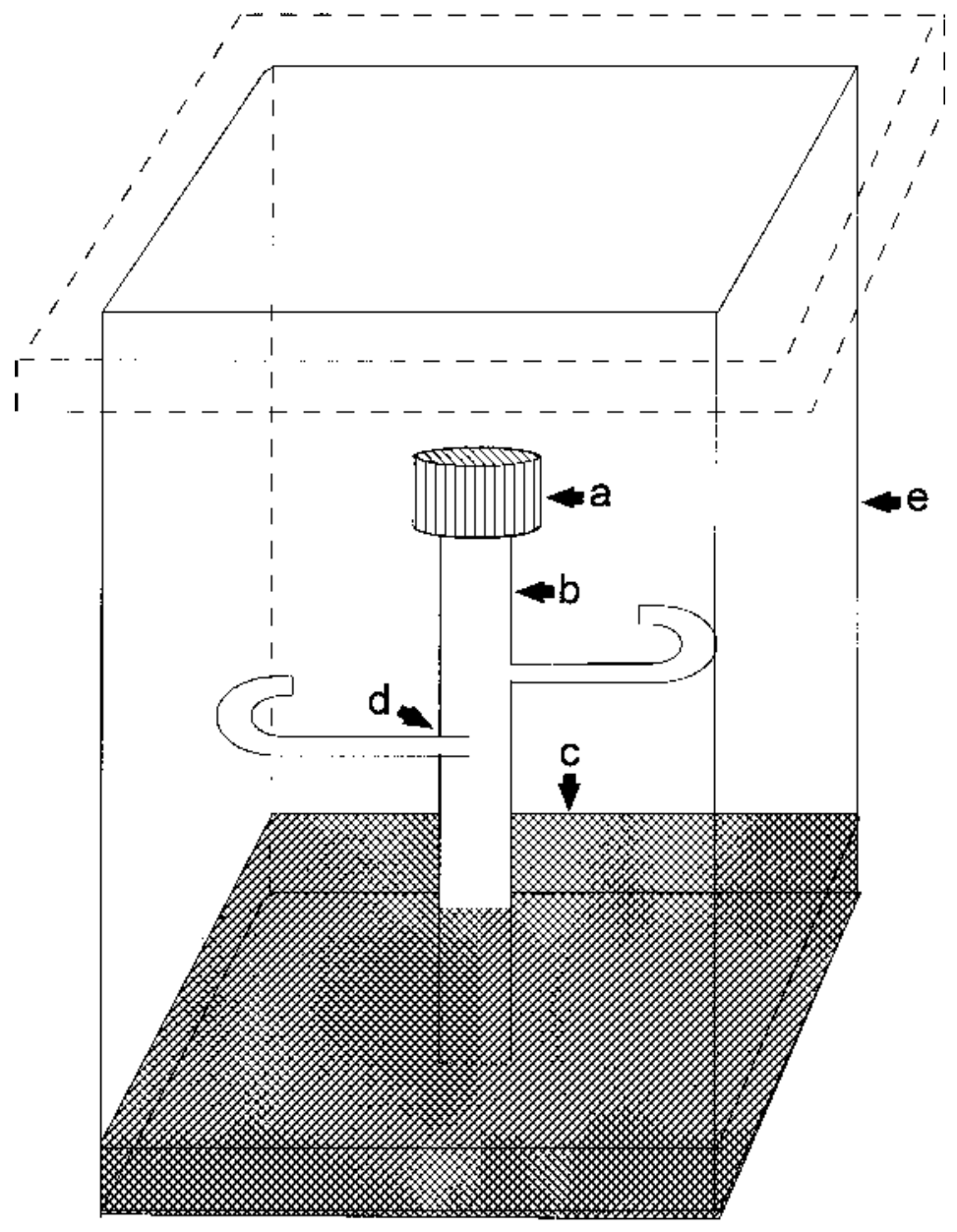

Fig. 1. Schematic diagram showing components of the experimental system used: (a) agar cylinder containing GA and IAA; (b) two-node medial sprout segment; (c) basal medium (MS) containing BA only; (d) rhizomes arising from nodal buds; (e) culture vessel.

Table 1. Effect of $\mathrm{GA}_{3}$ concentration in apical agar cylinder on 'Katahdin' potato rhizome development in two-node, medial sprout explants. ${ }^{\mathrm{z}}$ Results taken after 3 weeks in culture and means are the average of two experiments.

\begin{tabular}{|c|c|c|c|c|c|}
\hline \multirow{2}{*}{$\begin{array}{l}\mathrm{GA}_{3} \\
\text { concn } \\
\left(\mathrm{mg} \cdot \text { liter }^{-1}\right)\end{array}$} & \multicolumn{2}{|c|}{ Primary rhizome } & \multicolumn{2}{|c|}{ Secondary rhizome } & \multirow{2}{*}{$\begin{array}{c}\text { Rhizome } \\
\text { fresh wt } \\
(\mathrm{mg})\end{array}$} \\
\hline & No. & $\begin{array}{c}\text { Length } \\
(\mathrm{cm})\end{array}$ & No. & $\begin{array}{c}\text { Length } \\
(\mathrm{cm})\end{array}$ & \\
\hline$\overline{0}$ & 0 & 0 & 0 & 0 & 0 \\
\hline 0.2 & 1.04 & 1.25 & 0.93 & 1.13 & 154 \\
\hline 2.0 & $1.52^{* * *}$ & $2.02^{* *}$ & $1.94^{* *}$ & $1.55^{* *}$ & $185^{*}$ \\
\hline
\end{tabular}

${ }^{\mathrm{z}}$ Although IAA concentration also was varied, the main effects of IAA concentration and the IAA $\times$ GA interaction were nonsignificant.

${ }^{\mathrm{y}} \mathrm{n}=18$.

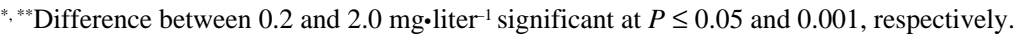

The ability of subterranean axillary buds to form rhizomes was related to darkness and high humidity associated with this location on intact potato plants (Kumar and Wareing, 1972). The system and conditions used by us attempted to duplicate those present in the below-ground portions of intact potato plants.

Results of our study, along with those from earlier work, support the role of endogenous growth regulators, specifically the gibberellins, in initiation and development of potato rhizomes.

\section{Literature Cited}

Booth, A. 1963. The role of growth substances in the development of stolons, p. 99-113. In: J.D. Ivins and F.L. Milthorpe (eds.). The growth of the potato. Butterworths, London.

Chapman, H.W. 1958. Tuberization in the potato plant. Physiol Plant 11:215-224.

Forsline, P.L. and A.R. Langille. 1976. An assessment of the modifying effect of kinetin on in vitro tuberization of induced and non-induced tissues of Solanum tuberosum. Can. J. Bot. 54:2513-2516. 
Jones, R.L. and I.D.J. Phillips. 1966. Organs of gibberellin synthesis in light-grown sunflower plants. Plant Physiol. 41:1381-1386.

Kumar, D. and P.F. Wareing. 1972. Factors controlling stolon development in the potato plant. New Phytol. 71:639-648.

Murashige, T. and F. Skoog. 1962. A revised medium for rapid growth and bioassays with tobacco tissue cultures. Physiol. Plant. 15:473496.
Okazawa, Y. 1960. Studies on the relation between the tuber formation of potato plant and its natural gibberellin content. Proc. Crop Sci. Soc. Jpn. 29:121-124.

Plaisted, P.H. 1957. Growth of the potato tuber. Plant Physiol. 32:445-453.

Wooley, D.J. and P.F. Wareing. 1972a. The role of roots, cytokinins and apical dominance in the control of lateral shoot form in Solanum andigena. Planta 105:33-42.
Wooley, D.J. and P.F. Wareing. 1972b. The interaction between growth promoters in apical dominance. I. Hormonal interaction, movement and metabolism of a cytokinin in rootless cuttings. New Phytol. 71:781-793.

Wooley, D.J. and P.F. Wareing. 1972c. The interaction between growth promoters in apical dominance. II. Environmental effects of endogenous cytokinin and gibberellin levels in Solanum andigena. New Phytol. 71:1015-1025. 